\title{
REALIZAÇÃO DA EPISIOTOMIA NOS DIAS ATUAIS À LUZ DA PRODUÇÃO CIENTÍFICA: UMA REVISÃO
}

\author{
Realization of the episiotomy in the current days \\ to the light of the scientific production: A revision \\ Realización de la episiotomía en los días actuales \\ a luz de la producción científica: Una revisión
}

Paulo Alexandre de Souza São Bento

Rosangela da Silva Santos

\section{Resumo}

A episiotomia é um procedimento cirúrgico realizado no períneo da mulher no momento do parto, feita por obstetras e enfermeiros obstetras. Atualmente tem sido empregada de forma rotineira, e esta prática vem sendo questionada. 0 presente estudo foi concebido a partir do levantamento bibliográfico da produção científica sobre episiotomia. Deu-se com busca eletrônica no banco de dados informatizado da LILACS. Foram levantados 60 estudos, sendo analisados 22 trabalhos sobre episiotomia especificamente, separados por décadas: 1980, 1990, e de 2000 a 2005. As discussões orientaram-se pela característica de estudo e do profissional que o produziu, e de que forma analisou a questão sobre a episiotomia. Conclui-se que a maioria dos estudos publicados sobre episiotomia foi elaborada por médicos, predominando os aspectos técnico-científicos e revelando-se o reflexo de uma formação cartesiana, com enfoque biologicista, também reflexo da visão política voltada à saúde da mulher, que ao longo dos anos foi definida como ser da reprodução, figura feita para o lar e para os filhos, ideologia impressa nos programas políticos que definiram a saúde deste grupo.

Palavras-chave: Saúde da Mulher. Enfermagem. Episiotomia.

\begin{abstract}
Episiotomy is a surgical procedure conducted by obstetricians and obstetrical nurses on the female perineum at the time of delivery. This procedure is adopted as routine in obstetrics, and its practice is currently being questioned. The present study was conducted beginning with bibliographical research of the scientific production regarding episiotomy. The bibliographical research for the present study was done with the help of search tools at the LILACS database. 60 studies were found, of which 22 specific papers on episiotomy, referring to the 1980s, 1990s and the period from 2000 to 2005, were analyzed. Discussions on the subject matter dealt with the study characteristics, the professional conducting the procedure and the manner of study of this procedure. Research indicates the majority of studies on episiotomy were done by doctors, whose main concern appears to be the technical and scientific aspects of the subject matter. This reflects a Cartesian background with a biological focus, as well as a political vision of feminine health, as a rule considering women reproductive beings whose most relevant roles are those connected to domestic, child-rearing activities, all in
\end{abstract}

\section{Resumen}

Este es un procedimiento quirúrgico realizado en el perineo de la mujer en la ocasión del parto, y es ejecutado por obstetras y enfermeros obstetras. Actualmente la episiotomía ha sido empleada de forma rutinaria e esta práctica viene sendo cuestionada. El presente estudio fué conducido a partir de la investigación bibliográfica de la producción científica a respecto de la episiotomía. La investigación bibliográfica se hizo por medio de busca electrónica en el banco de dados informatizado LILACS. Fueron reunidos 60 estudios, analizados 22 trabajos sobre episiotomía especificadamente, divididos por los periodos de las décadas de 80 y 90 e aquello entre los años de 2000 a 2005. Las discusiones se orientaron por la característica del estudio, el profesional quién lo condució y de que forma se estudió la episiotomía. Se concluye que la mayoría de los estudios publicados sobre la episiotomía fueron elaborados por médicos, con predominancia de los aspectos técnico-científicos como reflejo de una formación cartesiana, con enfoque biológico, también reflejo de una visión política para la salud de la mujer, que siempre la he definido como un ser reproductivo, creada para el lar y para los hijos, ideología impresa en los programas políticos que orientaron la salud en este grupo.
Keywords:

Woman's Health. Nursing. Episiotomy.
Palabras clave:

Salud de la Mujer. Enfermería. Episiotomía. 


\section{INTRODUÇÃO}

Este estudo teve como objetivo conhecer e analisar a produção científica sobre episiotomia registrada na base de dados da Literatura Latino-Americana e do Caribe em Ciências Sociais de Saúde (LILACS). Desta forma, também, buscamos novos conhecimentos em torno da prática da episiotomia, já que é um procedimento que data desde o século XVIII.

A discussão sobre a episiotomia é urgente nos dias atuais, quando a prática humanizada do atendimento ao parto e nascimento ganha, a cada dia, maiores proporções. Todas as práticas e procedimentos realizados no parto foram amplamente discutidos pela Organização Mundial de Saúde (OMS), incluindo a episiotomia; assim sendo, debates sobre a temática são oportunos. Até porque, em 2006, o programa da Organização Mundial de Saúde: Maternidade Segura Assistência ao Parto Normal: Um Guia Prático (OMS) fará 10 anos de divulgação.

0 Ministério da Saúde em 2003 retrabalhou os conceitos, práticas e condutas na assistência ao parto e lançou o manual Parto, Aborto e Puerpério: Assistência Humanizada à Saúde. Tomando por base as recomendações da OMS em 1996, o manual redefiniu as ações que devem ser implementadas no parto e nascimento. 0 material considera a episiotomia prática no parto normal claramente prejudicial ou ineficaz e que deve ser eliminada.

Quando se estuda humanização no atendimento à mulher, é imprescindivel que se trabalhe com pesquisas que justifiquem ou não determinadas condutas de assistência ao parto e nascimento. Em obstetrícia, muitas práticas foram instituídas sem respaldo científico e são utilizadas até a atualidade. No entanto, diversos estudos já foram realizados e demonstram que tais práticas são prejudiciais e que devem ser utilizadas com cautela ou até mesmo proscritas da assistência. Deste modo, ações como episiotomia de rotina não devem ser realizadas como outrora, pois a comunidade científica nos indica outro caminho.

As discussões sobre a temática não param por aqui. Sabemos que, independentemente de políticas ou tendências, pensamos na mulher como figura principal no momento do parto, estando ela inserida como centro das atenções, sujeito do processo parturitivo, e mais, como ser humano inserido em um contexto social. A mulher, como cidadã, na qual toda e qualquer prática, ato ou procedimento é realizado no seu corpo, deve ser analisada pelo que propriamente a define.

\section{REVISÃO DA LITERATURA}

A episiotomia é uma incisão cirúrgica realizada no períneo da mulher no momento da expulsão - segundo período do parto. 0 termo episiotomia vem de epision, que significa região pubiana, e tome, de incisão. Pode ser feita com tesoura ou bisturi, possui modalidades diferentes: perineotomia, médio-lateral e lateral. A sua sutura é feita com fio cirúrgico absorvível pelo organismo e é chamada de episiorrafia. Toda a técnica é asséptica e feita com utilização de anestésico ${ }^{1}$.

0 primeiro relato sobre este corte data de 1742 (século XVIII); ele foi criado por Felding Ould, que servia como "Second Master" em um hospital na Irlanda. Sir Ould defendia que a incisão só deveria ser aplicada quando necessário, em partos dificultosos, como intervenção utilizada para auxiliar o momento do parto ?

A incisão era realizada em linha média, e, em 1847, o Prof. Dubois, na França, foi o primeiro a levantar a modalidade médio-lateral. 0 termo "episiotomia" foi sugerido por Carl Braun em 1857. Cabe ressaltar que ela foi utilizada de forma criteriosa até o século XX ${ }^{2,3}$.

No início do século XX, com Pomeroy (1918) e Joseph DeLee (1920), a episiotomia passou a ser compreendida como procedimento de rotina. Pomeroy publicou um artigo intitulado: "Deveríamos cortar e reparar o períneo de todas as primíparas?". Sua posição foi em favor da episiotomia de rotina, justificando que o corte diminuía os traumas cranianos do bebê contra 0 assoalho pélvico. Pomeroy também trouxe a idéia de que a episiotomia recompõe a mulher em sua condição virginal. DeLee em 1920 defendeu, na Sociedade Americana de Medicina, o conceito de parto como processo patológico e, a partir disso, sugeriu a utilização do fórceps profilático e, com este, a episiotomia médio-lateral precoce, e o procedimento passou a ser recomendado como rotina ${ }^{2,3}$.

As alegações de DeLee para a realização da episiotomia rotineira incluíam: salvar a mulher do esforço do parto e do período expulsivo longo; preservar a integridade da musculatura pélvica e do intróito vulvar; evitar as pressões que 0 assoalho pélvico causa ao cérebro do bebê; e prevenir prolapso uterino, ruptura de quarto grau e condições virginais restabelecidas. Ao defender isto, DeLee não se pautou em evidências científicas, pois não havia nenhuma pesquisa que corroborasse tais evidências; no entanto, estes argumentos foram amplamente aceitos, e a episiotomia passou a ser feita de forma rotineira, baseada nestas indicações ?

DeLee e Pomeroy foram muito importantes como parte da história da obstetrícia no século XX. Podemos 
dizer que isso foi um marco histórico da episiotomia realizada de forma rotineira, pois definiu a utilização deste procedimento na assistência ao parto durante todo o século XX. Assim, tem sido ensinada até os dias atuais, e os livros técnicos de obstetrícia em suas várias edições ao longo dos anos (séculos XX e XXI) trazem estes conceitos ${ }^{3}$.

Em meados da década de 1980, começaram a surgir novas pesquisas sobre episiotomia - ensaios clínicos randomizados e controlados - que evidenciaram fatos contrários ao que DeLee preconizou no passado. Estes estudos, e outros realizados, culminaram no questionamento da eficácia e necessidade da episiotomia de rotina ${ }^{4}$. Um estudo português afirma:

Nos últimos vinte anos, múltiplos trabalhos tem tentado definir melhor as indicações e seqüelas associadas à episiotomia; a maioria conclui não haver suporte para acreditar que a sua prática generalizada diminua, por exemplo, o risco de lesão grave do períneo, melhore a sua cicatrização, previna a lesão fetal ou reduza o risco de incontinência urinária ${ }^{5: 448}$

Uma pesquisa colombiana mostrou, a partir de revisões sistemáticas e estudos aleatórios, que a prática rotineira da episiotomia não encontra suporte científico. Ela não previne a ocorrência de lacerações perineais, e pior, favorece a aparição de lesões de $3 .^{\circ}$ e $4 .^{\circ}$ graus ${ }^{6}$.

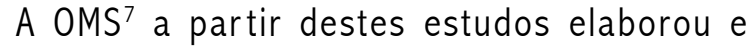
divulgou um manual técnico para atendimento ao parto e nascimento. Nele a episiotomia é inserida como procedimento amplamente realizado e que deve ser evitado.

Atualmente, dependendo do local, cerca de $90 \%$ das primigestas são cortadas. No Brasil e Argentina, por exemplo, praticamente todas as primigestas são submetidas à episiotomia. Muitas mulheres têm, anualmente, sua vulva e vagina cortadas cirurgicamente, mesmo se sabendo, hoje, que a episiotomia é um procedimento que deve ser utilizado apenas em 10/15\% dos partos. Podemos concluir que o restante de episiotomias são realizadas sem qualquer indicação clínica e sustentação científica, a não ser que opiniões pessoais, como as proposições de DeLee, sejam consideradas indicações 4,5,7,8.

Estudos de várias partes do mundo corroboram a falta de sustentação científica. Autores argentinos, colombianos, portugueses, americanos, ingleses, franceses, italianos, entre outros, colocam que a episiotomia é realizada de forma errada quando de rotina, uma vez que seu uso generalizado é desnecessário ${ }^{5,6,8,9}$.
Afora os problemas de indicação, respaldo científico, benefícios e riscos, critérios, taxas de utilização, pesquisas realizadas e crenças, a episiotomia é, acima de tudo, uma questão de gênero. Esta afirmação se fundamenta quando analisamos os significados atribuídos ao restabelecimento da musculatura vaginal e quando se levanta a questão do "ponto do marido", ou seja, a episiotomia quando suturada, diminui 0 diâmetro do diafragma vulvovaginal, "apertando" a entrada da vagina. Na concepção do "ponto do marido", traz-se a condição virginal à mulher e supõese que isto seja aprazível ao homem ${ }^{4}$, um procedimento realizado na mulher para satisfazer 0 homem. Como ficam as mulheres nesta história? A partir deste raciocínio, elas obtêm satisfação, pois se tornam "virgens" de novo e assim sendo, mantém "seu homem" feliz e para si. Esta questão também esbarra na ideologia de que o corpo feminino é pouco funcional e, portanto, necessita de reajustes para voltar ao estado "normal".

Obviamente, a episiotomia utilizada com este propósito se torna absolutamente desnecessária, afinal a vagina é composta por músculos. A mulher pode melhorar a força de sua musculatura vaginal por meio de exercícios. Neste sentido, ela aperfeiçoa seu desempenho vaginal, para 0 sexo e para o parto ${ }^{10}$. Devemos ressaltar que o prazer no ato sexual não se resume, somente, ao momento da penetração, da mesma forma que não se resume à continência ou não da vagina.

É penoso saber que com uma episiotomia desnecessária quando de rotina, feita sem indicação, a mulher pode ter dores e problemas sexuais durante muito tempo. Parteiras, em geral, não gostam de realizar episiotomias, o que nos leva a levantar a questão de que o corte possa refletir alguma insensibilidade masculina ${ }^{11}$.

É muito importante que a mulher conheça os problemas associados à episiotomia, compreendendo que podem ter musculatura perineal forte com a prática de exercícios e evitando uma episiotomia desnecessária, inclusive recusando o procedimento. Devem decidir sobre tudo o que é realizado no seu corpo, uma vez que a episiotomia tem sido considerada "lesão iatrogênica no parto", "agravo sexual iatrogênico", "ferimento sexual iatrogênico no parto" ${ }^{4}$.

A episiotomia de rotina tem sido considerada por vários autores como uma forma de mutilação genital, e mesmo como violência de gênero cometida pelas instituições e profissionais. 0 abuso de episiotomias tem sido considerado uma questão exemplar de desrespeito aos direitos humanos na área de saúde ${ }^{4: 1}$. 


\section{ABORDAGEM METODOLÓGICA}

Utilizamos a pesquisa bibliográfica para conduzir este estudo. Esta modalidade de pesquisa é realizada a partir de fontes teóricas já publicadas, como teses, artigos, revistas, etc. Ela pode ser feita de forma independente ou como parte de outras pesquisas, uma vez que, para qualquer pesquisa, há um levantamento bibliográfico prévio ${ }^{12}$.

A pesquisa bibliográfica é realizada com material que já recebeu tratamento escrito e elaborado. É importante não a confundir com pesquisa documental, uma vez que esta é realizada tendo em mãos material que não recebeu tratamento analítico ${ }^{13}$. A pesquisa documental procura dados primários, que vêm de órgãos que realizaram as observações e que são encontrados em arquivos, fontes estatísticas e fontes não escritas ${ }^{12}$.

Para o estudo, utilizamos como fio condutor: definição do tema, elaboração do plano de trabalho, identificação das fontes, busca eletrônica, tratamento dos dados com a respectiva classificação e documentação, análise destes dados e redação final ${ }^{13}$.

A escolha da temática deve estar em consonância com a inclinação e qualificação dos autores, pois, desta forma, torna a pesquisa agradável e interessante, para 0 autor e leitor ${ }^{13}$. Assim sendo, utilizamos o tema episiotomia, uma vez que o presente estudo faz parte da dissertação de mestrado "A Enfermagem e a Assistência à Mulher no Parto Normal: A Voz de Mulheres Submetidas à Episiotomia", pesquisa dos autores deste estudo, assim como temos interesse por todos os assuntos referentes à saúde da mulher. A pesquisa encontra-se registrada no Núcleo de Pesquisas de Enfermagem em Saúde da Mulher (NUPESM), do Departamento de Enfermagem MaternoInfantil da Escola de Enfermagem Anna Nery (EEAN) da Universidade Federal do Rio de Janeiro (UFRJ).

0 passo seguinte foi identificar as fontes e obter os materiais. Logo após, deu-se início à leitura, que foi realizada em três etapas. Primeiro - a leitura exploratória; segundo - leitura seletiva; e terceiro - leitura analítica. Uma vez realizada, seguiu-se para tomada de apontamentos e confecção das fichas de leitura identificando as fontes e registros dos conteúdos ${ }^{13}$.

Esta investigação constituiu-se pela busca eletrônica na base de dados LILACS. Para acessar os bancos de dados eletrônicos foi utilizado o descritor episiotomia. Todos os artigos foram selecionados, num total de sessenta.

Com este material passamos para o tratamento dos dados obtidos com leitura, fichamento, documentação e categorização. A partir disso, os dados foram submetidos à análise temática. Este tipo de análise possui um feixe de relações e pode ser graficamente apresentado através de uma palavra, frase ou resumo ${ }^{13}$. Finalizando com a fase redacional, buscou-se discutir o que é produzido sobre episiotomia pelos profissionais.

\section{APRESENTAÇÃO E DISCUSSÃO DOS RESULTADOS}

A partir do levantamento, foram encontrados 60 artigos no total. Destes, 22 são específicos sobre 0 tema episiotomia, e 38, sobre outros aspectos, mas que citavam a episiotomia em algum momento do texto.

Neste grupo, encontramos estudos sobre uso de vácuo-extrator na assistência ao parto, endometriose de região anal, análise da aplicação de fórceps, perfil etário de primigestas, entre outros.

Foram analisados, assim, 22 artigos específicos sobre episiotomia, categorizados por décadas, sendo estas: década de 1980, década de 1990 e 2000 até 2005. Na década de 1980, foram encontrados 8 trabalhos. Na década de 1990, foram levantados 9 trabalhos, e de 2000 a 2005, 5 trabalhos.

$\mathrm{Na}$ década de 1980, encontramos estudos realizados por médicos, por exemplo a pesquisa de BENATI ${ }^{14}$, que, por estudo duplo-cego comparativo com dose única de acetaminofeno, ácido acetilsalićlico e placebo em dor pós-episiotomia, revelou eficácia comparável aos agentes terapêuticos, mantendo-se superiores ao placebo. Outros estudos envolvendo uso de analgésicos foram feitos na década de 1980, como o de Padilla ${ }^{15}$, que avaliou o uso de aspirina e difunisal na dor pós-episiotomia, revelando que a aspirina tem bom efeito para dor e que, em casos em que esta dor seja muito intensa, pode-se usar o difunisal, por ser droga mais potente. Outra pesquisa realizada sobre efeito analgésico na época foi o de ROSAS PEREZ ${ }^{16}$. Outros estudos realizados na década destinaram-se a discutir aspectos sobre técnica, indicações, contraindicações, reparo e cicatrização, e um, sobre caso clínico de acidente de episiotomia ${ }^{17}$, no qual a mesma evoluiu para lesão de quarto grau. Os autores afirmam que a episiotomia foi necessária e enfatizam que, quando a conduta é correta, evolui favoravelmente. 0 único estudo ${ }^{18}$ diferente dos demais discutiu os riscos e benefícios do procedimento e defendeu o uso da episiotomia como instrumento protetor da musculatura pélvica.

Se antes na década de 1980 as pesquisas eram voltadas para a indicação, benefícios e modos de conter a dor da episiotomia, na década de 1990, as pesquisas refutavam algumas práticas utilizadas e questionavam 
o uso da episiotomia a partir de evidências científicas trazendo um novo olhar para a temática; e indicavam riscos na realização do procedimento. Foi quando surgiu o primeiro estudo com enfoque na percepção das mulheres e profissionais sobre a episiotomia. Nessa década, temos dois estudos realizados por enfermeiras.

Acrescentamos um estudo ${ }^{19}$ com 130 primíparas, no qual encontramos a ocorrência de lesões de IV grau e o aparecimento de incontinência fecal em mulheres nas quais a episiotomia foi empregada. Há, ainda, estudos de caso de endometriose na cicatriz de episiotomia, prática de antibioticoterapia para episiotomia, revelando que o uso do antibiótico profilático não traduz diferenças estatisticamente significativas ${ }^{20}$. Há também estudos sobre melhor fio cirúrgico para realização da rafia e sobre as complicações relacionadas ao procedimento, este último realizado por enfermeiras.

Nessa década, uma dissertação de mestrado defendida por uma enfermeira ${ }^{21}$ destoou dos demais estudos ao discutir a percepção das mulheres e profissionais sobre a episiotomia. Nela ficou evidente que as orientações fornecidas às puérperas são centradas no procedimento; que as instituições hospitalares não abordam o parto sem episiotomia, entre outros aspectos levantados na pesquisa.

A partir de 2000 até 2005, as cinco pesquisas desenvolvidas apontaram uma nova abordagem para o velho tema. Em 2000, o artigo intitulado: "Episiotomia de rotina: as evidências contra" ${ }^{3}$ revelou a existência de várias pesquisas realizadas que refutavam os benefícios antes alegados sobre episiotomia e que concluíram que esta não deve ser praticada de forma rotineira. Outro estudo 22 questionou o que há de verdade na episiotomia e considerou que não tem efeito protetor do períneo.

Em 2002 surgiu uma pesquisa ${ }^{23}$ sobre endometriose na cicatriz da incisão e outra ${ }^{2}$ que questionava, no título, se "Devemos continuar fazendo a episiotomia de forma rotineira?". 0 artigo foi amplamente divulgado e conhecido, concluindo que a realização do procedimento de forma rotineira surgira em princípios do século XX. Baseava-se em crenças pessoais e sem justificativa científica. Hoje se recomenda, nacional e internacionalmente, que a episiotomia seja utilizada de forma especifica e de acordo com a necessidade da parturiente.

De todos os trabalhos pesquisados, vinte foram produzidos por médicos, e dois, produzidos por enfermeiras. A baixa produção científica de enfermeiras em assuntos relacionados a parto e nascimento, aqui especificamente a episiotomia, pode ser pensada pelo reduzido número de enfermeiros que atuam diretamente na assistência ao parto. É ainda pequeno o número de enfermeiros obstetras, e estes enfrentam resistências por parte de alguns obstetras que ainda acreditam que a (o) enfermeira (0) é subordinada (o) a eles e que devem estar prontas (os) a servir, ignorando o próprio conhecimento de enfermagem ${ }^{24}$. Ainda nesta análise encontramos:

Ser enfermeiro neste cenário de prática da obstetrícia significa sustentar e nos impormos a cada momento na luta diária do "campo", buscando estabelecer mudanças e transformações no consenso, ou seja, senso comum, e assim impormos nossa forma de lidar, pensar assistir em obstetrícia 24:147.

Algo surpreendente encontrado nesta imersão foi que, dos 22 artigos analisados, todos eles apresentaram enfoque cartesiano a partir dos aspectos técnico-científicos, clínicos e físicos. Nenhum estudo desenvolveu uma abordagem compreensiva ou investigou a vivência, o cotidiano, o emocional e/ou cultural da mulher em que pesem os valores sociais construídos historicamente. Outro achado de suma relevância foi que, de todas as 22 pesquisas, somente 1 analisou a temática do ponto de vista da mulher, as 21 restantes discutiram o procedimento cirúrgico. Devese ressaltar que a formação acadêmica e as políticas públicas têm importante contribuição neste sentido.

A formação acadêmica dos profissionais da área da saúde, mormente, médicos e enfermeiras, ainda é cartesiana e positivista. Profissionais de saúde são formados para discutir e trabalhar os aspectos biológicos do ser humano e com enfoque curativo centrado na doença. A nossa política sempre estabeleceu metas em obstetrícia a partir de coeficiente de mortalidade materna, alto índice de cesárias e mortes por causas preveníveis ${ }^{25}$, e isso reflete 0 direcionamento do olhar das políticas públicas para a doença, e não para a saúde.

Ao falar de "cultura de nascimento", encontramos a idéia do corpo como máquina a ser controlada. No caso da mulher, esta "máquina" é ainda considerada defeituosa e que, uma vez com "problemas técnicos", precisa ser consertada. O hospital é visto como a indústria, com tecnologia desenvolvida, destinada a estas máquinas e seus produtos - os bebês. Já encontramos em alguns livros a definição de feto e/ou recém-nascido como produtos da concepção ${ }^{26}$.

Dentro deste enfoque, na formação profissional, ainda encontramos currículos voltados, em sua maioria, para a prática curativa. Com relação à obstetrícia, por 
exemplo, a maior parte dos obstetras está preocupada com a doença, e não com a saúde. Isso é decorrente de sua formação, já que passam boa parte do seu tempo estudando os aspectos patológicos de determinado fenômeno. No caso do parto, ignora-se sua fisiologia e o considera problema em potencial ${ }^{11}$.

0 livro-texto mais indicado para a prática obstétrica no Brasil considera a episiotomia um instrumento de grande valia na proteção do períneo e estimula seu uso, já que 0 define como benéfico, sem nem mesmo questionar as contra-indicações, as possibilidades de não ser empregada. Agregamos a isso também a ideologia das políticas públicas na área de saúde da mulher que perduraram até 0 ano de 2004, refletindo o pensar de grande número de profissionais e da própria mulher, os quais são produtos da mesma cultura. Cabe ressaltar que, em cursos de Graduação de medicina e enfermagem, este livro é muito difundido e utilizado. Por outro lado, os conteúdos programáticos das instituições revelam ordenação vertical e utilização de bibliografia restrita e centrada nas ciências médicas (obstetrícia, ginecologia, neonatologia e pediatria) ${ }^{27}$. Em relação à formação da enfermeira obstetra, temos que: "no perfil desta formação ainda predomina o modelo biomédico, cujo destaque operacional do processo ensino-aprendizagem centra-se no caráter tecnicista" 27:167. Deste modo, por ser a formação profissional alicerçada a partir deste paradigma, preocupa-nos o fato de ser a enfermagem uma profissão majoritariamente feminina e as enfermeiras ainda não valorizarem, não se preocuparem ou não se sensibilizarem com as questões de gênero relacionadas à mulher que é submetida à episiotomia.

A postura profissional e de grande parte das mulheres é influenciada pelas Políticas Públicas de Saúde, especialmente na área de saúde da mulher. De 1974 até a implementação do PAISM, tínhamos o Programa Nacional Materno-Infantil (PNSM), com as ações voltadas prioritariamente às demandas do ciclo gravídico-puerperal, com vistas à redução da razão da morbimortalidade materno-infantil; assistência materna; assistência à criança e ao adolescente; aumento da cobertura da assistência materno-infantil; capacitação de recursos humanos; e assistência no pré-concepcional e pré-nupcial. A ideologia deste Programa priorizava o fortalecimento das especialidades nos moldes capitalistas e a integração social. Destacavam-se, ainda, os aspectos biológicos, e a mulher ainda era vista como objeto da reprodução e feita para o lar. Em 1984, o Programa de Assistência Integral à Saúde da Mulher (PAISM) ampliou a atuação com ações educativas, preventivas, de diagnóstico e tratamento. Procurou assistir a mulher em várias etapas do ciclo de vida, da menarca à menopausa. Apesar de valorizar a equidade e integralidade da assistência, a ideologia dominante visava o processo de municipalização e fortalecimento da atenção básica para atender ao perfil epidemiológico da mulher enquanto sujeito da reprodução. A partir daí é fácil entender, pelo ponto de vista político, por que estudos sobre episiotomia das décadas de 1980 e 1990 tinham o caráter tecnicista e verticalizado, uma vez que os programas de atenção também focavam a mulher neste sentido ${ }^{28}$.

As pesquisas surgidas em 2000, 2001 e 2002 trazem nova abordagem em relação aos estudos relacionados à episiotomia e já corroboram as várias pesquisas surgidas sobre 0 novo olhar na assistência à mulher e aos programas de parto e nascimento humanizado, que surgiram com a $\mathrm{OMS}^{7}$ e com 0 Ministério da Saúde (MS), que investigaram as práticas realizadas no parto e estabeleceram diretrizes para a assistência. Especificamente, em relação à episiotomia liberal ou rotineira, a OMS ${ }^{7}$ classificou-a como prática freqüentemente utilizada de modo inadequado, e o MS, como prática no parto normal claramente prejudicial ou ineficaz e que deve ser eliminada.

Em 2004, foi lançada, pelo Ministério da Saúde, a Política Nacional de Atenção Integral à Saúde da Mulher, que veio coadunar com todas as novas perspectivas na assistência à mulher, agora com enfoque de gênero, direitos sexuais e reprodutivos, violência doméstica e sexual, ampliando o olhar para a atenção à mulher. É importante ressaltar não só a mudança de nomenclatura, de Programas para Política, mas também a mudança de ideologia, considerando a mulher a partir das relações sociais e de gênero como sujeito de cidadania ${ }^{28}$.

A atual política foi estruturada com a participação de diversos grupos sociais, de mulheres, negros, sociedades científicas, ONG, entre outros, sublinhando a importância de se valorizarem a fala, o cotidiano, opiniões, necessidades, expectativas e vários outros aspectos importantes que interferem em toda e qualquer prática na assistência à mulher.

Como sujeito da cidadania, compreende-se que as mulheres participem ativamente sobre toda escolha a ser feita em seu corpo, atuando e decidindo sobre sua vida. A participação social é fundamental para a construção do processo democrático e o crescimento da relação entre o poder público e a cidadania.

Participação é definida como fazer parte, tomar parte ou ter parte. Com ela facilita-se o crescimento da consciência crítica da população, reforçando sua reivindicação para adquirir mais poder na sociedade ${ }^{29}$. 
Neste sentido, é factível e necessário que profissionais de saúde moldem suas práticas em função do respeito e direito das mulheres de decidirem sobre suas vidas corpo e mente. Assim sendo, a mulher deve ser entendida como cidadã por profissionais e instituições.

Este enfoque de gênero e cidadania representa a importância das relações igualitárias entre homens e mulheres. A Conferência Internacional da ONU sobre população e desenvolvimento, realizada no Cairo em 1994, e a IV Conferência Mundial sobre a Mulher, realizada em Pequim em 1995, enfatizaram a necessidade de se promover a igualdade entre homens e mulheres, isso como requisito fundamental para conquista de melhores condições de saúde e qualidade de vida, de envolvimento e responsabilidade entre homens e mulheres nas questões de saúde sexual e reprodutiva, assim impresso em março de 2005 no manual de Direitos Sexuais e Reprodutivos: Uma Prioridade do Governo ${ }^{30}$.

0 manual composto por sete cadernos a respeito de planejamento familiar, abortamento, violência sexual contra a mulher, adolescentes, anticoncepção, entre outros, valoriza a igualdade entre homens e mulheres nas questões referentes à saúde sexual e reprodutiva, ressaltando que este processo é delineado a partir de valores éticos e morais e da incorporação de comportamentos e atitudes diante de uma estrutura de padrões sociais e sexuais influenciados pelas relações de gênero, raça e etnia, estabelecidos social e culturalmente.

\section{CONSIDERAÇÕES FINAIS}

As atuais concepções acerca da episiotomia ainda são pouco exploradas e adotadas por profissionais da área da saúde, mas trazem novas perspectivas no que concerne a este procedimento realizado na mulher. 0 que vemos hoje, ao analisarmos as recomendações sobre o uso restrito da episiotomia, é algo como um retorno histórico a quem o criou, Felding Ould, que também

\section{Referências}

1. Tortora GJ. Corpo humano fundamentos de anatomia e fisiologia. $4^{\text {a }}$ ed. São Paulo (SP): ArtMed; 2003.

2. Tomasso G, Althabe F, Cafferata M, Alemán A, Sosa C, Belizán J. Devemos seguir haciendo la episiotomia em forma rutinaria? Rev Obstetrícia e Ginecologia , Venezuela, 2002 jun; 62(2): 115-21.

3. Labrecque M, Eason E, Daniels F, Ymayo MR, Bourget MM. Episiotomia de rotina: as evidências contra. Diagnóstico e tratamento 2000 jul; 5(2): 43-50. advogava a utilização em casos excepcionais, ou seja, não recomendava seu uso rotineiro. Com isso evidencia-se no século XX as indicações de DeLee, em 1920 perpetuadas, e põe-se em foco as proposições dele sobre a episiotomia; desta forma, novos horizontes são avistados.

0 primeiro estudo encontrado a partir do levantamento realizado data de 1984. E hoje, após 21 anos, podemos afirmar que o perfil das pesquisas centra-se na avaliação da episiotomia como procedimento cirúrgico, analisando suas indicações, contra-indicações, complicações, tratamento e seu uso institucional. Somente um estudo avaliou a percepção da mulher sobre a episiotomia e focou os aspectos clínicos desta. Dos 22 artigos encontrados, somente dois foram de autoria de enfermeiros, sendo o restante de autoria de médicos. A pequena produção científica de enfermeiras sobre a temática pode ser justificada no déficit de enfermeiras obstetras, na relação de poder existente no campo profissional e, desta forma, na pouca atuação direta da enfermagem na assistência ao parto. De qualquer forma, é preocupante saber que as enfermeiras, sendo mulheres, não despertaram ainda para estudos envolvendo um procedimento realizado no corpo feminino, que tem a ver com a sexualidade, com o gênero e a cultura.

A escassez de trabalhos sobre a episiotomia na perspectiva feminina é resultado de uma formação tecnicista dos profissionais, que valorizam mais a doença/instrumentalização do que a saúde/prevenção. Assim sendo, é "mais fácil" advogar pela utilização da episiotomia, que vem intervir para "auxiliar" o períneo da mulher, do que defender a prática de exercícios no sentido de prevenir a ocorrência de lacerações perineais e necessidade do emprego da mesma.

0 estudo evidenciou que a voz da mulher não é valorizada, pois não existem estudos na perspectiva de gênero. Isso depende de mudanças na concepção e ideologia da utilização da episiotomia, não só como procedimento cirúrgico, mas como prática social, atrelada a valores diversos delineados historicamente.

4. Diniz S. Campanha pela abolição da episiotomia de rotina. Fique amiga dela. [periódico on line] 2004 ago; [citado 10 ago 2004]; [aprox. 4 telas]. Disponível em: http://www.mulheres.org.br/ fiqueamigadela/episiotomia.htlm

5. Borges BB, Serrano F, Pereira F. Episiotomia: uso generalizado versus selectivo. Acta Médica Portuguesa 2003 fev; (16): 447-54.

6. Rubio JA. Política selectiva de episiotomia y riesgo de desgarro perineal em um hospital universitário. Rev Colombiana de Obstetrícia y Ginecologia 2005 abr/jun; 56: 2. 
7. Organização Mundial de Saúde-OMS. Assistência ao parto normal: um guia prático. Relatório de Grupo Técnico. Genebra; 1996.

8. Lardizábal J, Cingolani S, Martínez L. Episiotomia. parto feliz. [periódico on line] 2006 mar; [citado 20 mar 2006]; [aprox. 2 telas]. Disponível em: http://www.partofeliz.com.ar/episiotomia.htm

9. Carpanzano C. L'episiotomia. L'ostetrica informa. [on line] 2006 mar; [citado 20 mar 2006]; [aprox. 9 telas]. Disponível em: http:// uww.lostetricainforma.it $/$ modules.php?name $=$ News\&file $=$ article\&sid $=7$.

10. Paciornik M. Aprenda a envelhecer sem ficar velho. $3^{\mathrm{a}}$ ed. Curitiba (PR): Ed. Goulart; 1997.

11. Odent M. 0 renascimento do parto. Tradução de Roland B. Calheiros. Florianópolis (SC): Saint-Germain; 2002.

12. Rampazzo L. Metodologia científica: para alunos dos cursos de graduação e pós-graduação. 2. ${ }^{a}$ ed. São Paulo (SP): Loyola; 2004.

13. Dias IMAV, Marchionatti C, Santos RS. A produção científica sobre vacinação na literatura brasileira de enfermagem no período de 1973 a 1999. Esc Anna Nery Rev Enferm 2003 abr; 7(1): 57-68.

14. Benati CJ. Estudo duplo-cego comparativo com dose única de acetaminofen, acido acetilsalicilico e placebo, no tratamento da dor pós-episiotomia. J Bras Ginecol 1984; 94(5): 191-97.

15. Padilla de Gil M. Difunisal vrs aspirina em el dolor post-episiotomía: estúdio comparativo. Rev Med Costa Rica 1987 jul; 54(500): 123-25.

16. Rosas Perez O, Salinas AF. Valoracion del efecto analgésico y tolerabilidad de suprofen y dipirona em pacientes com dolor debido a episiotomia. Invest Med Int 1986 set; 13(2): 105-08.

17. Manso Regalado V, Alemán Ramírez PE, Aguila García MA. Accidente quirúrgico poço frecuente en la episiotomía: presentación de um caso. Rev Cubana Obstetrícia e Ginecologia 1989 jan; 15 (1/2): 107-12.

18. Amar I, Soares MMO. A episiotomia: riscos e benesses. Arq Bras Med 1989 mar/abr; 63 (2): 79-81.

19. Fonseca Morales JV. Determinación de incontinência fecal por lesiones ocultas del esfínter anal durante el parto vaginal con episiotomía media em primigestas. Rev sanidad Militar 1998 nov/dez; 52(6): 355-58.

20. Saab Neto JA, Gonçalves LFA. Avaliação clínica do emprego do cloranfenicol como antibiótico profilático no parto normal com episiotomia. ACM-Arq Catarinense de Medicina 1990 abr/jun; 19 (2): 97-102.

21. Riffel MJ. Episiotomia: a dimensão oculta [dissertação de mestrado]. Porto Alegre (RS): Universidade Federal de Santa Catarina/ Universidade Federal do Rio Grande do Sul; 1997.
22. Martins-Costa S, Ramos JGL, Brietzke E, Stuczinski JV, Dias EC. Episiotomia: o que há de verdade neste tradicional procedimento? Femina 2001 maio; (29): 201-04.

23. Díaz-Barreiro G, Niño Sánchez A. Endometriosis em la cicatriz de episiotomia y em vagina. Informe de um caso y revisión de la literatura. Ginecologia y Obstetricia, México, 2002 jun; 70(6): 281-84.

24. Vasconcelos SDD. Dominação e autonomia: os elementos básicos da enfermagem obstétrica [dissertação de mestrado]. Rio de Janeiro (RJ): Escola de Enfermagem Anna Nery/UFRJ; 2001.

25. Martins CA. O Programa de Assistência Integral à Saúde da MulherPAISM em Goiânia: a (des) institucionalização da consulta de enfermagem no pré-natal. [tese de doutorado]. Rio de Janeiro (RJ): Escola de Enfermagem Anna Nery/UFRJ; 2001.

26. Davis-Floyd R. Del medico al sanador. Buenos Aire(AR): Creavida; 2004.

27. Silva HCFS. Programas de ensino de enfermagem obstétrica: análise dos marcos estruturais [dissertação de mestrado]. Rio de Janeiro (RJ): Escola de Enfermagem Anna Nery/UFRJ; 1995.

28. Araújo CF, Tyrrell MAR. Exposição oral sobre Políticas da Mulher no Brasil. Política e problemática na saúde da mulher no Brasil. Rio de Janeiro (RJ): UFRJ/CCS/EEAN; abril. 2005

29. Dias-Bordenave JE. 0 que é participação. 8. ${ }^{a}$ ed. São Paulo (SP): Brasiliense; 1994.

30. Ministério da Saúde (BR). Direitos sexuais e direitos reprodutivos: uma prioridade do governo. Brasília (DF); 2005.

\section{Sobre os Autores}

\section{Paulo Alexandre de Souza São Bento}

Aluno do Curso de Mestrado da Escola de Enfermagem Anna Nery/ UFRJ. Enfermeiro do Instituto Estadual de Infectologia São Sebastião - RJ e Professor Auxiliar da Fundação Técnico Educacional Souza Marques - RJ.

\section{Rosangela da Silva Santos}

Professora Titular do departamento de Enfermagem materno-Infantil da Escola de Enfermagem Anna Nery/UFRJ. Membro da Diretoria do Núcleo de Pesquisa em Saúde da Mulher - NUPESM/DEMI/EEAN/ UFRJ. Presidente da ABENFO Nacional. 